\title{
Global changes in gene expression associated with phenotypic switching of wild yeast
}

Vratislav Štovíček ${ }^{1,3}$, Libuše Váchová2,1, Markéta Begany², Derek Wilkinson ${ }^{1}$ and Zdena Palkováa ${ }^{*}$

\begin{abstract}
Background: Saccharomyces cerevisiae strains isolated from natural settings form structured biofilm colonies that are equipped with intricate protective mechanisms. These wild strains are able to reprogram themselves with a certain frequency during cultivation in plentiful laboratory conditions. The resulting domesticated strains switch off certain protective mechanisms and form smooth colonies that resemble those of common laboratory strains.

Results: Here, we show that domestication can be reversed when a domesticated strain is challenged by various adverse conditions; the resulting feral strain restores its ability to form structured biofilm colonies. Phenotypic, microscopic and transcriptomic analyses show that phenotypic transition is a complex process that affects various aspects of feral strain physiology; it leads to a phenotype that resembles the original wild strain in some aspects and the domesticated derivative in others. We specify the genetic determinants that are likely involved in the formation of a structured biofilm colonies. In addition to FLO11, these determinants include genes that affect the cell wall and membrane composition. We also identify changes occurring during phenotypic transitions that affect other properties of phenotypic strain-variants, such as resistance to the impact of environmental stress. Here we document the regulatory role of the histone deacetylase Hda1p in developing such a resistance.

Conclusions: We provide detailed analysis of transcriptomic and phenotypic modulations of three related S. cerevisiae strains that arose by phenotypic switching under diverse environmental conditions. We identify changes specifically related to a strain's ability to create complex structured colonies; we also show that other changes, such as genome rearrangement(s), are unrelated to this ability. Finally, we identify the importance of histone deacetylase Hda1p in strain resistance to stresses.
\end{abstract}

Keywords: Biofilm colony, Histone deacetylase, Phenotypic switching, Wild yeast strains

\section{Background}

In the natural environment, microorganisms do not exist in stable and optimal growth conditions. Instead, microbial populations are often challenged by harmful external factors. The formation of complex multicellular communities, such as biofilms or colonies, provides an advantage for survival in the wild due to the cooperative behavior of cells and the establishment of common protective mechanisms [1]. Moreover, the adaptive responses of individual cells and their phenotypic heterogeneity, factors that enable efficient adaptation to a rapidly changing environment, are also important characteristics that allow populations to thrive in natural settings. Phenotypic switching is a mechanism by

\footnotetext{
* Correspondence: zdenap@natur.cuni.cz

'Department of Genetics and Microbiology, Faculty of Science, Charles University in Prague, Viničná 5, 12844 Prague 2, Czech Republic Full list of author information is available at the end of the article
}

which phenotypic heterogeneity is achieved. This process generates cell phenotypes that are better adapted to a particular environment, thereby allowing a population to react flexibly to environmental changes [2]. In yeast, phenotypic switching generates a diverse array of changes, leading to the emergence of colonies with altered morphologies [3]. The appearance of different colonies occurs more frequently than somatic mutations. Although relatively stable during subsequent passages, the switched variants retain the ability to revert to their original phenotype [4].

Phenotypic switching is a phenomenon that is commonly observed in pathogenic yeasts [5]. Switching occurs at infection sites to generate phenotypes that effectively evade the host immune response [6]. The new phenotypes also exhibit features that contribute to increased virulence $[7,8]$. A phenotypic switch is defined as a random event that is not necessarily induced by external factors; however,

\section{Biomed Central}


environmental conditions can affect the frequency and direction of the switch. For example, certain strains of Candida albicans undergo a transition from a "white" to "opaque" colony phenotype and vice versa. Exposure to temperatures above $30^{\circ} \mathrm{C}$ increases the frequency of switching to the "white" phenotype [9]. Thus, white cells predominate in the blood stream at a physiological temperature of $37^{\circ} \mathrm{C}$, whereas "opaque" cells more efficiently colonize the skin surface, an environment with a lower temperature [7]. Furthermore, anaerobic conditions and other environmental factors also mediate the transition to the "opaque" phenotype [10]. Thus, switching provides a mechanism of adaptation to certain niches and to a variety of physiological conditions.

Wild Saccharomyces cerevisiae strains isolated from their natural habitat also exhibit phenotypic heterogeneity and the ability to switch between two or more different colony phenotypes [11-15]. During laboratory cultivation on rich media, the switch is usually oriented toward the formation of less-structured colonies that differ in many features from their structured counterparts [14]. Such a switch, that we term "domestication" [13] results in the formation of strains that are stable during subsequent passages on agar media and that form smooth colonies similar to those formed by standard $S$. cerevisiae laboratory strains [13]. The formation of a domesticated derivative, BR-S, of the wild S. cerevisiae BR-F strain on a nonfermentable medium occurs efficiently with an average frequency of approximately 2-3\% [13]. This frequency suggests that switching is caused by a regulated event rather than by random mutations. During cultivation of a BR-S strain under adverse conditions, we demonstrate the occurrence of reverse phenotypic changes that lead to the re-appearance of cell clones that form more structured colonies. We termed these strains "feral" strains. By comparing the transcriptomes of the original wild BR-F strain, its domesticated BR-S derivative and the feral BR-RF strain (the strain that restored biofilm colony formation), we determine the genome-wide expression alterations involved in phenotypic changes. In addition, we specify the factors involved in the formation of structured biofilm colonies. Finally, we show that at least some individual strain properties are under the control of epigenetic mechanisms and that recombination and genome rearrangements occur during phenotypic switching.

\section{Results}

Feral subclones derived from a BR-S strain under stress conditions form structured colonies

To induce the conversion of a BR-S strain to a strain with a wild-type phenotype, the opposite process of domestication, we set up various stressful and long-term starvation conditions. We incubated the BR-S strain statically (i.e., without shaking) for several months in various media with a limited carbon source. During incubation in MM medium with $2 \%$ ethanol, the number of colony-forming units (CFU) in the suspension was monitored. In parallel, the morphology (structured versus smooth) of the arising microcolonies was determined on GMA plates (Figure 1A). After inoculation, the static cell culture grew slowly until approximately the 60 th day, as indicated by the slowly increasing number of CFU. From approximately the 75th day, the number of CFU started to decrease, suggesting a gradual dying of part of the population (Figure 1A). During this period, the number of cells forming smooth colonies decreased to a rate of about $5 \times 10^{4}$ cells per $\mathrm{ml}$ of culture per day. Colonies with a structured morphology started to appear rarely among the smooth colonies on the 28th day or later. The frequency of their appearance reached approximately $0-7 \%$ of the CFU (Figure 1A). Interestingly, between days 30 and 110 , the number of cells forming structured colonies increased to a rate of up to 400 to 2000 cells per $\mathrm{ml}$ of the culture per day in parallel cultures. Thus, at later stages of static cultivation (140 days), the proportion of structured colonies increased to as high as 26\% (Figure 1A). In some static cultivations the cells forming structured colonies reached as high as $40 \%$ of all CFU (not shown). Structured colonies also emerged in static cultivations with MM medium that contained lower or higher ethanol concentrations. In addition, colonies appeared in cultivations without any carbon source, in which ethanol was replaced with $\mathrm{NaNO}_{3}$. When ethanol was replaced with fructose, structured colonies only appeared when the starting fructose concentration was $0.5 \%$ or lower; with a fructose concentration of $1-2 \%$, no structured colonies were observed in cultivations lasting more than 200 days.

The morphology of the emerging structured colonies was not uniform, varying from moderately structured to a fully structured colony phenotype. We classified the emerging colonies into four typical colony phenotype categories (Figure 1B). Most of the isolated subclones were unstable; after re-plating, these colonies domesticated at a high frequency, thus preventing a more detailed characterization. The most stable subclones formed colonies of the $I V^{\text {th }}$ category, phenotypically resembling biofilm colonies of the original wild BR-F strain. One of these subclones, designated BR-RF, was used for further analyses.

\section{The BR-RF strain domesticates more efficiently than the original wild BR-F strain}

With the aim of monitoring the stability of the BR-RF strain, we compared the frequency of its domestication on fermentative and respiratory media (evaluated as the frequency of formation of smooth colonies) with that of the BR-F strain (Figure 1C). In BR-F colonies, the percentage of domesticated subclones ranged from $0.05 \%$ (4-day-old colonies) to $2.6 \%$ (22-day-old colonies) when grown on 
A
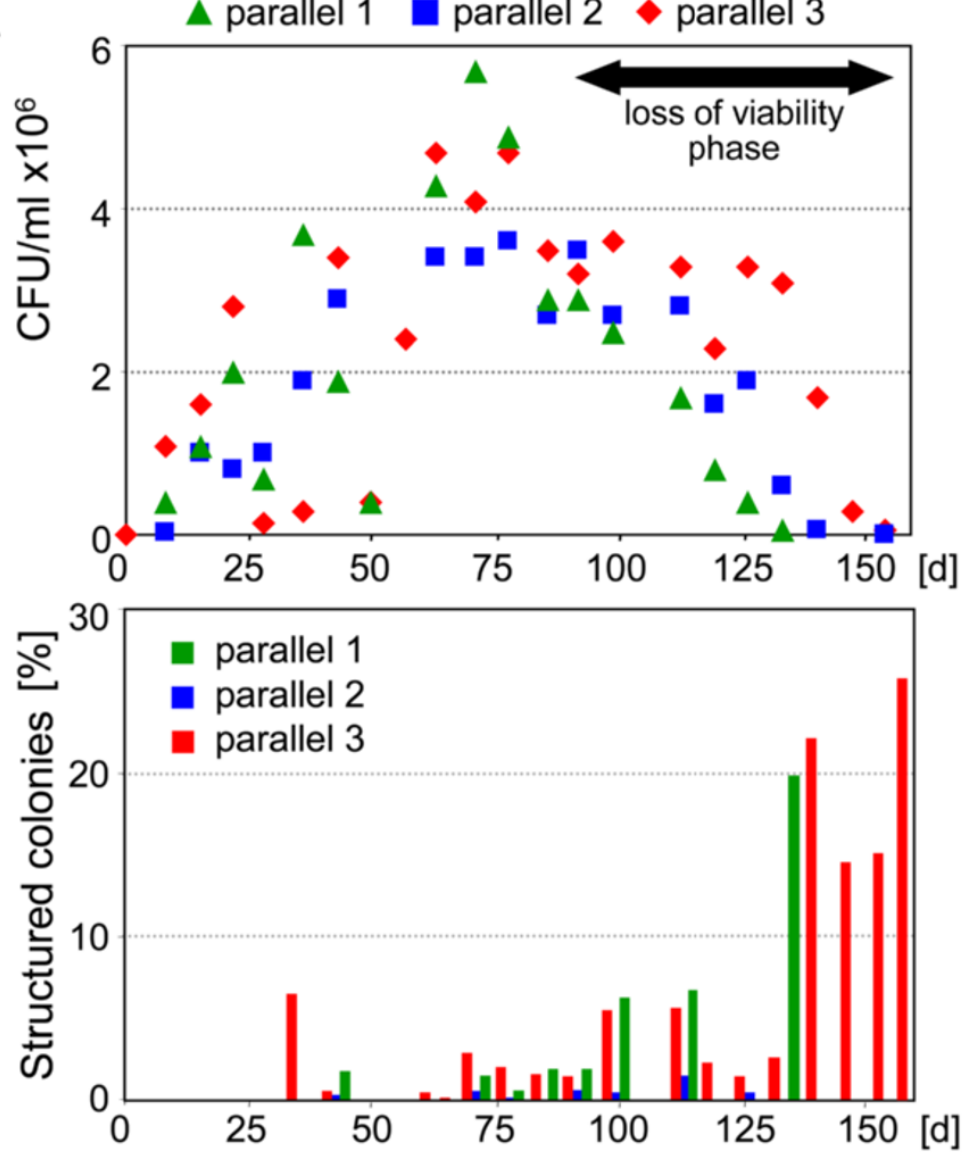

B

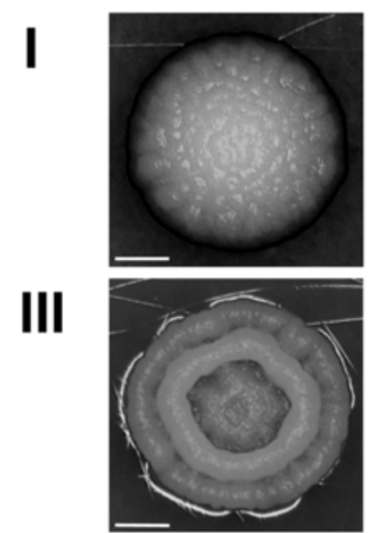

II

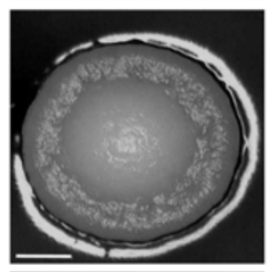

IV

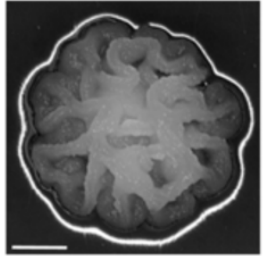

C
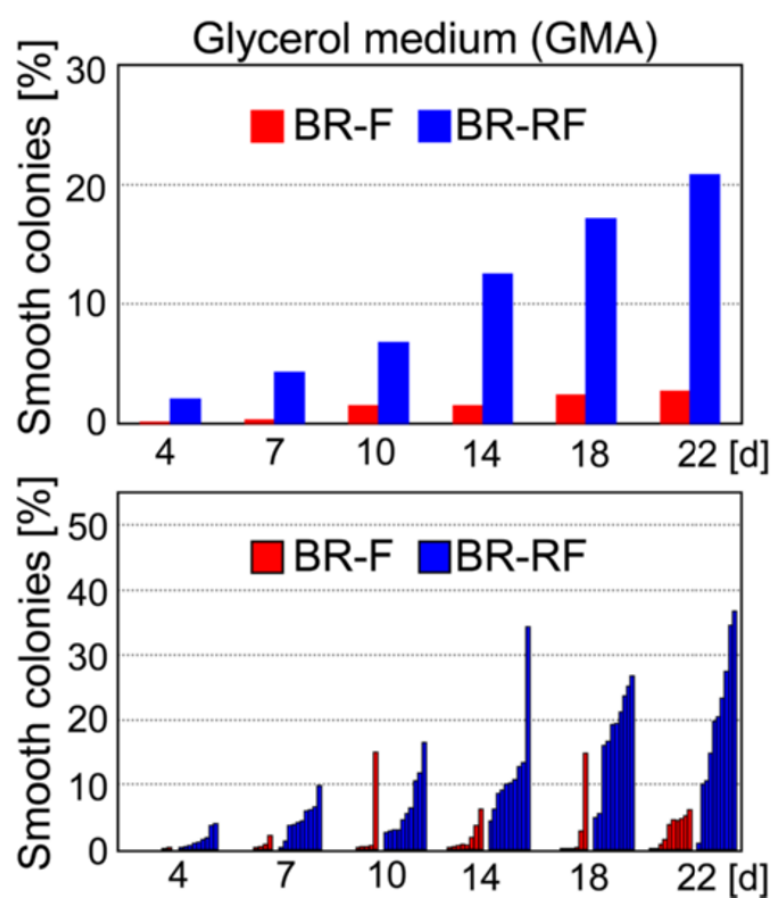

Glucose medium (YEGA)
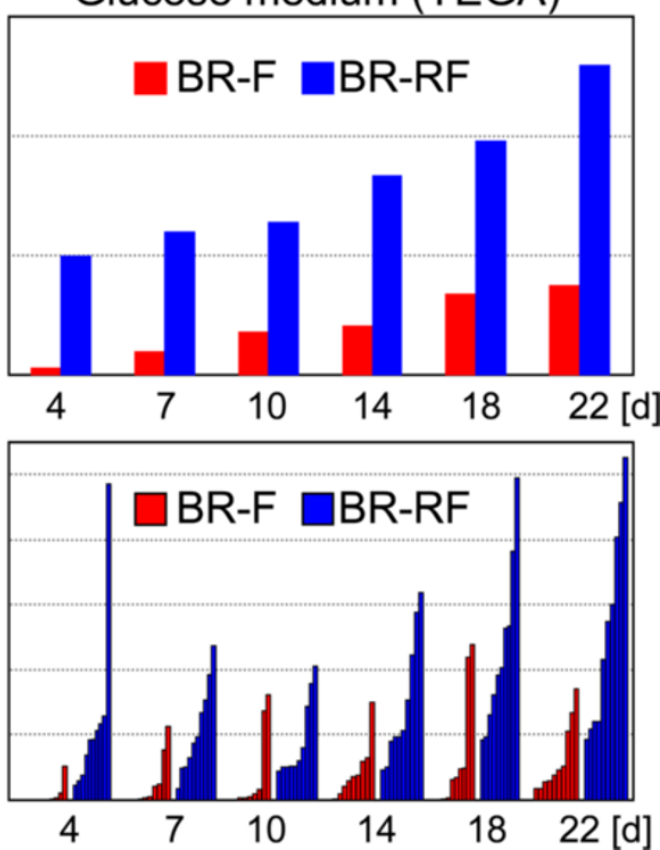

Figure 1 (See legend on next page.) 
(See figure on previous page.)

Figure 1 Origin and stability of the BR-RF strain. A. Upper panel, growth curve of 3 parallel static cultures of the BR-S strain in MM-2\% ethano medium, expressed as CFU/ml. Lower panel, appearance of cells forming structured colonies (switched phenotype) expressed as a percentage of total colony number. A representative experiment of the three is shown. B. Colonies with structured morphology originating from the BR-S strain during cultivation in static culture. From the top, morphotypes I, II, III and IV (the latter named BR-RF). Scale bar $=1 \mathrm{~mm}$. C. Domestication frequency of colonies of the BR-F and BR-RF strains. The upper graphs represent the average appearance of smooth colonies after the re-plating of BR-F (red columns) and BR-RF (blue columns) colonies relative to the total CFU of all re-plated colonies. The bottom graphs show the switching frequencies of individual colonies, BR-F (red columns) and BR-RF (blue columns).

respiratory medium and from $0.6 \%$ (4-day-old colonies) to $7.5 \%$ (22-day-old colonies) when grown on fermentable medium (Figure 1C, upper graphs). In individual BR-F colonies, the frequency of domesticated subclones varied from $0 \%$ to $15 \%$ on respiratory and from $0 \%$ to $24 \%$ on fermentable medium (Figure 1C, bottom graphs). In BR-RF colonies grown on respiratory GMA, domesticated subclones appeared with an average frequency of $2 \%$ (4-day-old colonies) to $21 \%$ (22-day-old colonies), with variation in individual colonies from $0 \%$ to $37 \%$. Similar to BR-F domestication, the frequency of BR-RF domestication was even higher when the BR-RF colonies were grown on fermentable
YEGA; domestication varied from 10\% (4-day-old colonies) to $26 \%$ (22-day-old colonies), with variation in individual colonies from $2 \%$ to $53 \%$ (Figure $1 \mathrm{C}$ ).

\section{Morphology and physiology of colonies formed by the BR-RF strain}

The morphology of colonies (bird's-eye view) formed by the BR-RF strain was identical to that of colonies formed by the original BR-F strain (Figure 2A). Two-photon excitation confocal microscopy (2P-CM) confirmed that the BR-RF colony was composed of an aerial part and of subsurface roots attaching the colony to the substrate. This

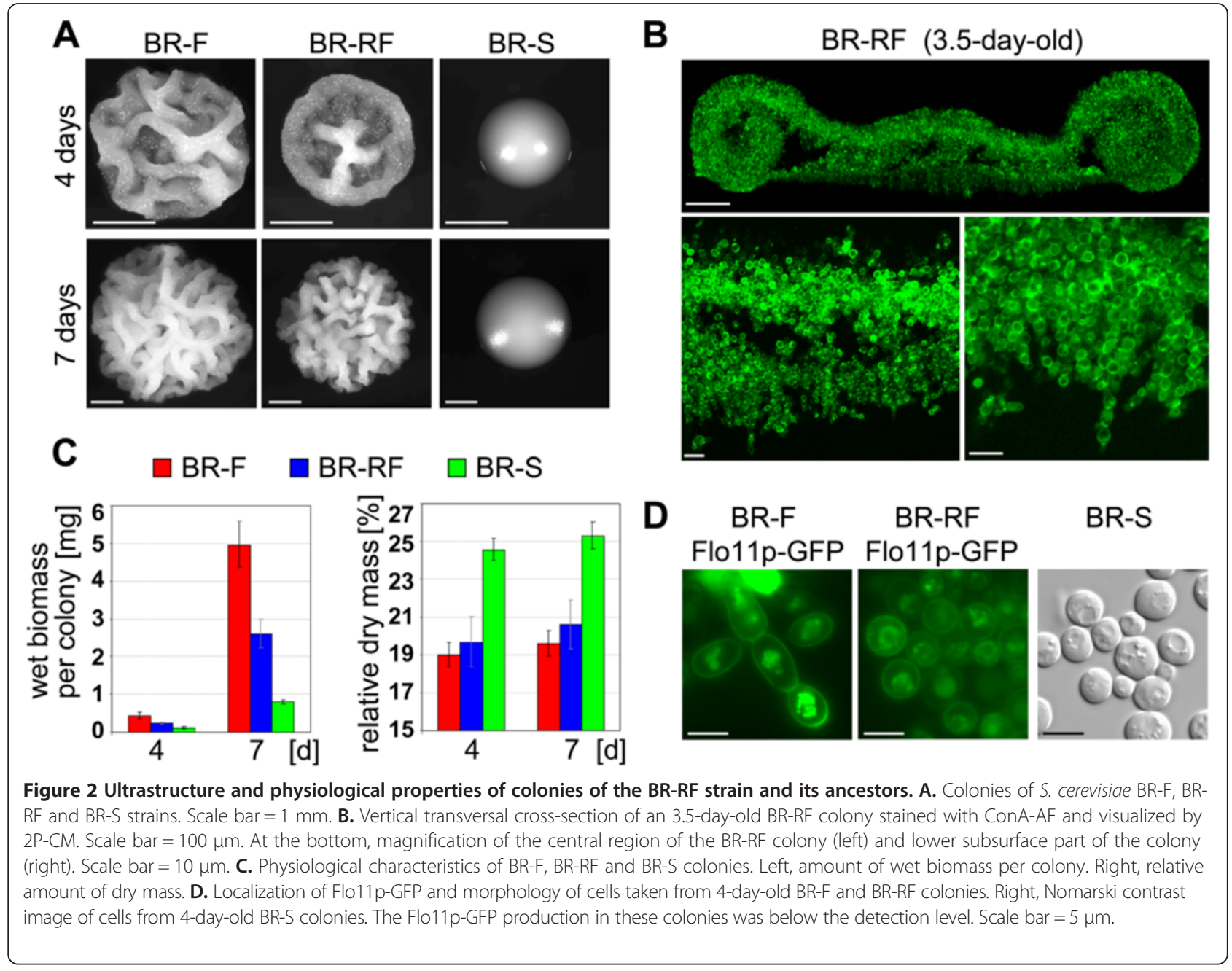


composition is similar to the organization of the BR-F colony [16]. The colonies of both strains contained internal cell-free cavities (Figure 2B). In contrast to BR-F colonies [16], BR-RF colonies were formed exclusively of oval cells, including the subsurface parts where chains of oval cells invaded the agar (Figure 2B) instead of the pseudohyphae that are typical of BR-F colonies. Thus, although the BR-RF strain gained the ability to form fully structured colonies, it did not revert its cell morphology and retained the oval cells typical of the BR-S strain (Figure 2D).

Although they formed similarly structured colonies, BR-F and BR-RF strains may have differed in other physiological parameters. We therefore analyzed BR-RF colonies grown on GMA for prominent characteristics previously found to be different between colonies formed by the BR-F and BR-S strains [14]. The analysis revealed that in some aspects, BR-RF colonies behaved as an "intermediate" between BR-F and BR-S colonies. This intermediate behavior was mostly related to wet biomass accrual (Figure $2 \mathrm{C}$ ) and colony size (Figure 2A), while the water content (relative amount of dry mass) of BR-RF colonies was almost identical to BR-F colonies (Figure 2C).

Another typical feature of BR-F colonies was the presence of high-molecular-weight glycosylated protein (HMWGP), a possible constituent of the extracellular matrix (ECM). The production of HMWGP was switched off in BR-S colonies [13]. BR-RF colonies restored production of this protein, but at a lower level than in BR-F colonies. In addition, SDS-PAGE showed that the mobility of this protein was shifted to lower MW. This observation suggested that the molecule was shortened or underwent less glycosylation (Figure 3A). The presence of HMWGP (an ECM constituent) and a high content of water, possibly trapped by ECM [14] implied that BR-RF colonies restored ECM production. To demonstrate presence of ECM we prepared a BR-RF-P GAL1 GFP strain to monitor the ECM in the developing colony by $2 \mathrm{P}-\mathrm{CM}$, as previously described [16]. As in BR-F colonies [16], internal BR-RF

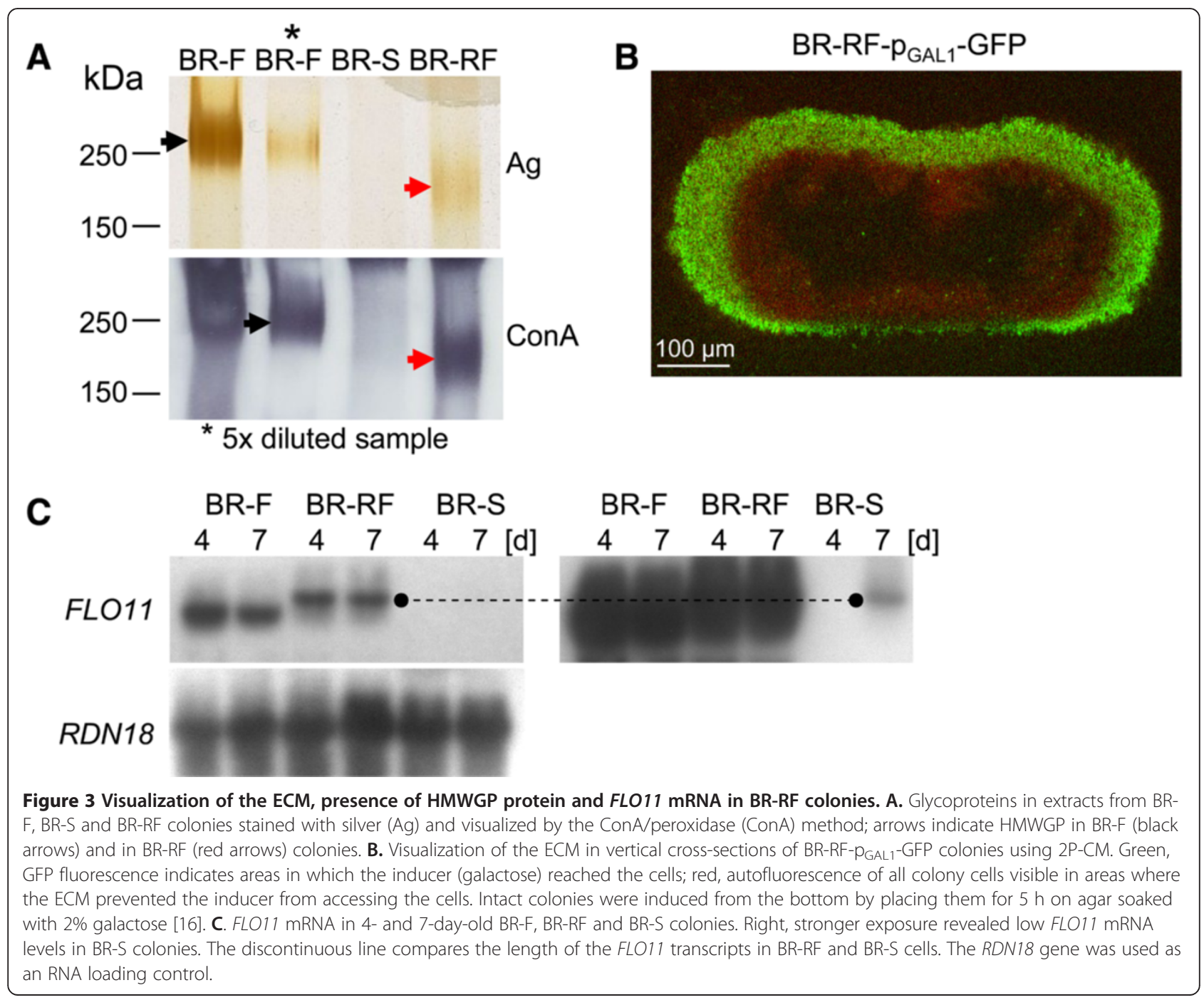


colony regions were also protected via a low-permeable ECM (Figure 3B).

The production of the adhesin Flo11p is indispensable for the formation of structured colonies [14,17], and Flo11p production is switched off during wild strain domestication [13]. Both FLO11 gene expression (Figure 3C) and Flo11p protein production (Figure 2D) are recovered in the BR-RF strain. Interestingly, the FLO11 mRNA of the $\mathrm{BR}-\mathrm{RF}$ strain is longer than that of the BR-F strain (Figure 3C).

\section{Genome-wide expression differences between BR-F, BR- RF and BR-S colonies}

To obtain an overall view of the transcription characteristics typical of the biofilm colony phenotype, we isolated total RNA from 4-day-old and 7-day-old colonies formed by the BR-F, BR-S and BR-RF strains. We then compared the transcriptomes of the BR-RF versus BR-F strain, the BR-RF versus BR-S strain and the BR-F versus BR-S strain using a microarray (Additional file 1: Table S1). Mutual comparison of the transcribed genes enabled the identification of genes specifically activated or repressed in complex structured biofilm colonies (represented by the BR-F and BR-RF strains) compared to smooth colonies (represented by the BR-S strain) (Table 1). However, the expression differences related to the structured biofilm colony phenotype were only a subset of the expression differences observed between the strains. Other extensive differences unrelated to the colony phenotype were observed between BR-RF and BR-F colonies, as well as between BR-RF and BR-S colonies. Some of these differences are summarized in Figure 4 and discussed below. This finding supports the data described above indicating that some properties of

Table 1 Functional classification of genes up-regulated in particular colony phenotypes

\begin{tabular}{|c|c|c|}
\hline & Structured biofilm colony morphotype & Smooth colony morphotype \\
\hline Cell wall & SVS1, ASP3-1,-2,-3,-4, BSC1, OSW5 & SPS100, CTS1, FLO9, PFS1, PSA1, ZPS1 \\
\hline $\begin{array}{l}\text { Secretory } \\
\text { transport \& } \\
\text { processing }\end{array}$ & $\begin{array}{l}\text { BST1, LST7, PER1, CWH41, MNN9, YOL107W, } \\
\text { APM4, GVP36, YIP4 }\end{array}$ & BTN2, NCE102, GYP7, KTR4, PEP12, SNC2, TIM17, TIM21 \\
\hline Metabolism & $\begin{array}{l}\text { JLP1, MLS1, SNZ1, SNZ2, TPI1 - YMR226C, } \\
\text { BNA1, ENO1, HPT1, MDH2, RHR2, SOL4 }\end{array}$ & DSF1, PIG2, STR3, CRS5, CUP1-1, FBP26, FOL2, FRE6, HXK1, MTD1, NFS1, SFA1 \\
\hline Amino acids & $\begin{array}{l}\text { ARG3, ARG4, BAT1, MET17, MET22, ARG1, } \\
\text { GDH3, LAP3 }\end{array}$ & GCV1, GCV2, GCV3, SHM2 \\
\hline Lipids \& fatty acids & INO1 - ECI1, POT1, POX1, TES1, VPS66 & YNL144C, ERG3, ERG4, HFD1 - AUR1, CEM1, CSG2, SUR1, SUR4 \\
\hline Nucleotides & & RNR4 - ADE1, ADE2, ADE8, ADE13, PRS3 \\
\hline Transport & $\begin{array}{l}\text { ITR1, PUT4, VHT1, PDR12, VBA3, ATO2, } \\
\text { CAN1, GAP1, MEP2, PIC2 }\end{array}$ & $\begin{array}{l}\text { YFL054C HXT15, MUP3, PHO84, THI74, ZRC1, HXT5, HXT17, PHO89, YFLO54C, } \\
\text { HXT1, HXT2, HXT3, HXT4, HXT6, HXT10, HXT12, HXT13, MAL11, PHO87, ZRT2 }\end{array}$ \\
\hline Degradation & HSP33, MGR1, NAS2, YSP3 & ATG8, BSD2, CIC1, DFG16, GID8, JID1, UMP1, RPN5, RPN13, RPT2, SNA3, VID24, YPT53 \\
\hline Stress response & $\begin{array}{l}\text { DDR48, GRX3 - TSA1, YBLO36C, CTA1, SOD2, } \\
\text { TSA2 }\end{array}$ & $\begin{array}{l}\text { OLA1, HSP42, SPG1, SSA3, SSA4, APJ1, FES1, GPX1, HSP30, HSP78, SSE1, } \\
\text { YNL190W, AAD6, CCT5, CPR6, GLO1, GSH1, HSP104, HSP150, MGE1, OYE3, PST1, } \\
\text { RCN2, SED1, STI1, TRX3, YDJ1,YGP1 }\end{array}$ \\
\hline \multicolumn{3}{|l|}{ Regulation } \\
\hline $\begin{array}{l}\text { Translation \& RNA } \\
\text { processing }\end{array}$ & $\begin{array}{l}\text { BRR2, MTQ2, SLF1, DUS4, SPP381, IST3, } \\
\text { MRS2, RPP1A, RPR2 }\end{array}$ & $\begin{array}{l}\text { PUS2, SLH1, NGL3, RPA135, RSC30, YDR341C, CBF5, SRO9, RPP2A, RPS3OB, RPL35B, } \\
\text { RRP3, RRP7, SRC1 }\end{array}$ \\
\hline Signal transduction & FAR3 & $\begin{array}{l}\text { GPA2, MTH1, MRK1, STD1, LST8, RGS2, YMR291W, GLC8, HRK1, KIC1, MTH1, STE7, } \\
\text { YAK1 }\end{array}$ \\
\hline Cell cycle \& polarity & SHE1 & PCL9, HBT1, TAH11, CLG1, CDC13, CDC3, DSE1, VHS1 \\
\hline Transcription & $\begin{array}{l}\text { CUP9, SFG1, TEC1, YAP7, } \\
\text { DAL80, RDS1 }\end{array}$ & $\begin{array}{l}\text { YFL052W, HMS1, RLM1, USV1, ZPR1, ALPHA2, CIN5, GIS1, HAP4, OPI1, PHO2, } \\
\text { STP2, STP4 }\end{array}$ \\
\hline $\begin{array}{l}\text { - chromatin } \\
\text { structure }\end{array}$ & HHF1 & TOS8, IOC4, HHT1, TMA23,TOD6 \\
\hline $\begin{array}{l}\text { General } \\
\text { transcription }\end{array}$ & & IWR1, RBA50, RPA135, SPT15, SUA7, TAF12, TFA1 \\
\hline Transposons* & 8 genes, 10 genes, 1 genes & \\
\hline Unknown* & 7 genes, $\mathbf{5}$ genes, 17 genes & 8 genes, $\mathbf{4}$ genes, 11 genes \\
\hline Others & & YLR164W, DIA1, DIA3, MRH1, MRPS17, IXR1, PIN3 \\
\hline
\end{tabular}

Genes only expressed differently on the 4th day are in standard letters, genes differently expressed on both the 4th and 7th day are in bold, and genes only expressed differently on the 7th day are italicized.

* genes are listed in the Additional file 1: Table S1 and discussed in the text. 


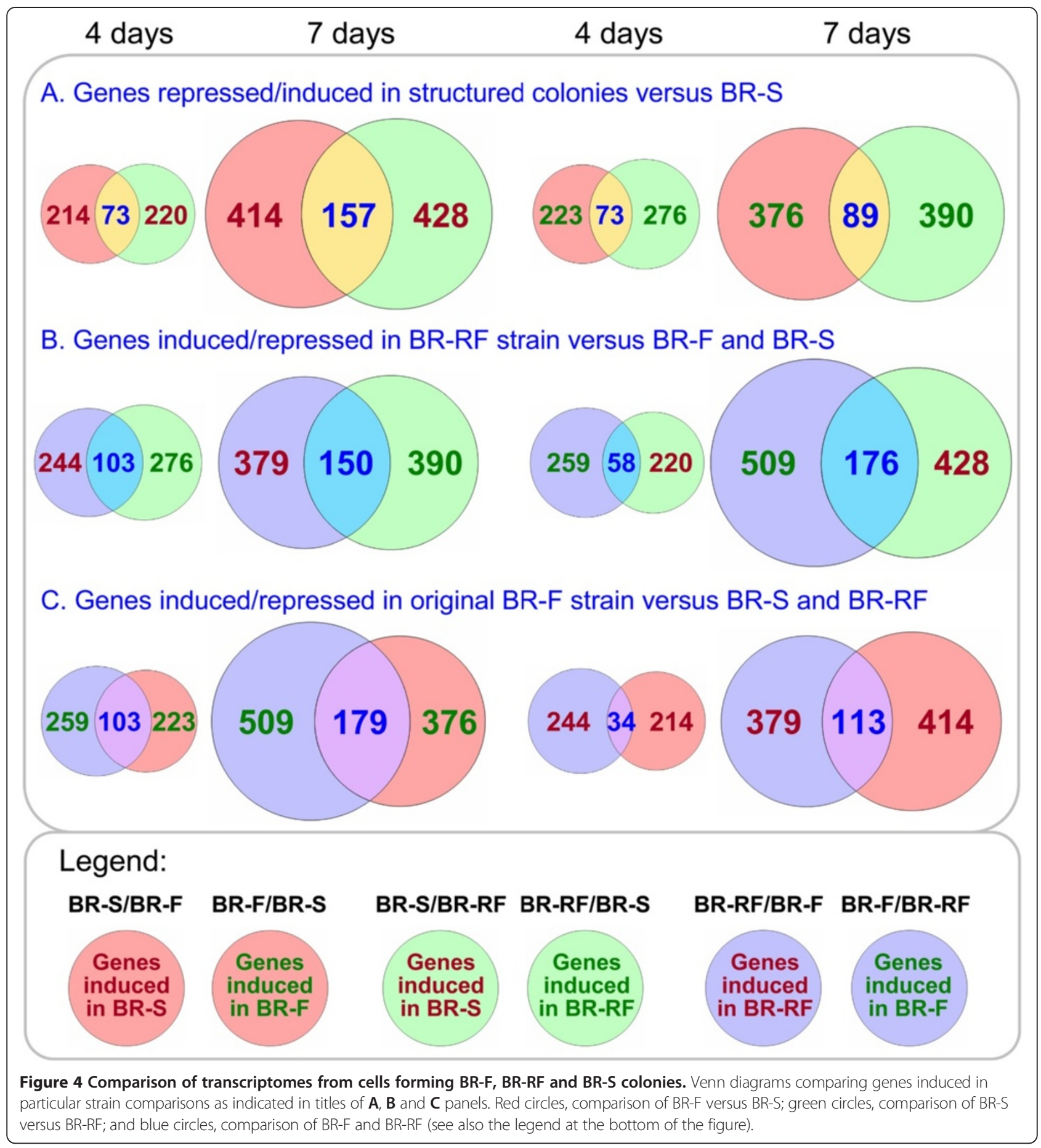

BR-RF colonies differ from colonies formed by both BR-F and BR-S.

\section{Expression characteristics of complex biofilm colonies} Comparison of the structured biofilm colony versus the smooth colony transcriptomes revealed 73 and 89 genes with significantly higher expression in 4- and 7-day-old structured colonies, respectively. In smooth colonies, the expression levels of 73 and 157 genes were increased in 4- and 7-day-old colonies, respectively (Figure 4, Table 1, Additional file 1: Table S1).

The structured biofilm colonies up-regulated genes involved in protein secretion and modification. Some of these genes, such as MNN9, CWH41, BST1 and PER1, influence the structure and the composition of the cell wall and/or the membrane. In addition, the structured 
colonies highly up-regulated genes for cell wall proteins such as BSC1, which is similar to the FLO11, and ASP3 genes. On the other hand, the structured colonies downregulated the expression of other cell wall-related genes such as SPS100 and CTS1 as well as genes related to secretion and protein modification. These data indicate that structured and smooth colonies differ in the carbohydrate and protein composition of their cell wall (Table 1).

The structured and smooth colonies also differed in their expression of metabolic genes and nutrient transporters. The structured colonies up-regulated amino acid metabolism genes and transporter genes, including genes involved in arginine and methionine metabolism. The structured colonies also expressed genes involved in phospholipid biosynthesis and fatty acid $\beta$-oxidation, and they expressed the inositol transporter gene ITR1. In contrast, the few amino acid metabolism genes that were up-regulated in the smooth colonies were for the mitochondrial glycine decarboxylase complex. The smooth colonies also up-regulated a number of nucleotide metabolism genes, genes involved in copper and iron resistance and homeostasis and several genes related to lipid metabolism. These included genes involved in ergosterol, sphingolipid and ceramide metabolism (ERG3, SUR1, SUR4, CSG2). The transporter genes included those for the transport of hexoses and phosphate (PHO84, PHO87) (Table 1).

In addition, the smooth colonies up-regulated a large group of genes related to the stress response (28 genes), including genes for various chaperones, genes involved in cell wall stress response/maintenance and certain genes involved in the oxidative stress response. The few stress response genes induced in structured colonies included oxidative stress response genes (GRX3, TSA1, TSA2, CTA1 and SOD2) and genes involved in DNA damage response and repair (DDR48, YBL036C, DDI3 and $R A D 10$ ) (Table 1 ).

The cells of structured and smooth colonies also differed in their expression of a remarkable number of genes involved in signaling cascades (1 gene upregulated in the structured and 13 genes in the smooth colonies), transcription regulators (6 genes up-regulated in the structured and 13 genes in the smooth colonies) and genes involved in translation and RNA processing (9 genes up-regulated in the structured and 14 genes in the smooth colonies). The transcription factor genes upregulated in the structured colonies included TEC1 and SFG1, which are involved in yeast filamentation and pseudohyphal growth. In contrast, the smooth colonies up-regulated RLM1, YFLO52W and USV1, which are related to cell wall integrity. They also up-regulated several genes related to chromatin structure and remodeling (TOS8, TOD6, TMA23, IOC4 and HHT1) (Table 1).
In addition, the structured colonies predominantly expressed genes for transposons and a large group of genes with unknown function, some of which were localized to the subtelomeric regions (Table 1).

\section{BR-RF colonies up-regulated expression of genes located at specific positions in chromosomes}

BR-RF colonies increased the expression of 244 genes and 379 genes in 4- and 7-day-old colonies, respectively, compared with BR-F colonies. BR-RF colonies reduced the expression of 259 genes and 509 genes in the 4- and 7-day-old colonies, respectively, compared to BR-F colonies. For the comparison between the BR-RF and BR-S strains, BR-RF colonies increased the expression of 276 genes and 390 genes in 4- and 7-day-old colonies, respectively, compared to BR-S colonies (including typical "biofilm colony" genes, see above). BR-RF colonies repressed 220 and 428 genes in 4- and 7-day-old colonies, respectively, compared to BR-S colonies. In addition, a relatively large number of genes were up-regulated (103 genes in 4-day-old and 150 genes in 7-day-old colonies) and down-regulated (58 genes in 4-day-old and 176 genes in 7-day-old colonies) in BR-RF colonies when compared with both BR-F and BR-S colonies (Figure 4).

"Positional Gene Enrichment" analysis revealed that many gene expression differences between the BR-RF strain and either the BR-F or BR-S strain (or both) involved the expression of genes localized to specific chromosomal regions (Figure 5) rather than genes randomly distributed in the genome. Most prominently, a high number of genes up-regulated in 4-day old colonies of BR-RF strain were localized to a $300-\mathrm{kbp}$ region of the left arm of chromosome XV. This region included $33 \%$ of all activated genes in the BR-RF versus BR-S strain, $32 \%$ of all activated genes in the BR-RF versus BR-F strain and $60 \%$ of all activated genes in the BR-RF versus both BR-S and BR-F strains. Smaller groups of genes up-regulated in the BR-RF strain versus either the BR-S or BR-F strains were localized to a $320-\mathrm{kbp}$ region of chromosome IX, and a group of BR-RF strain genes that were down-regulated compared to the BR-F and BR-S strains was localized to a $240-\mathrm{kbp}$ region of chromosome XII (Figure 5). In contrast, neither the gene expression differences between the BR-F and BR-S strains, nor the genes expressed specifically in structured biofilm colonies (i.e., those differently expressed between the BR-F and BR-RF strains versus the BR-S strain) were localized to specific chromosomal regions (not shown).

As the higher level of gene expression related to distinct chromosomal areas could be caused by DNA duplications, we measured the copy numbers of 3 genes located in the left arm of chromosome XV (the genome region with higher expression in BR-RF), relative to those of 3 genes located in the right arm of the same 


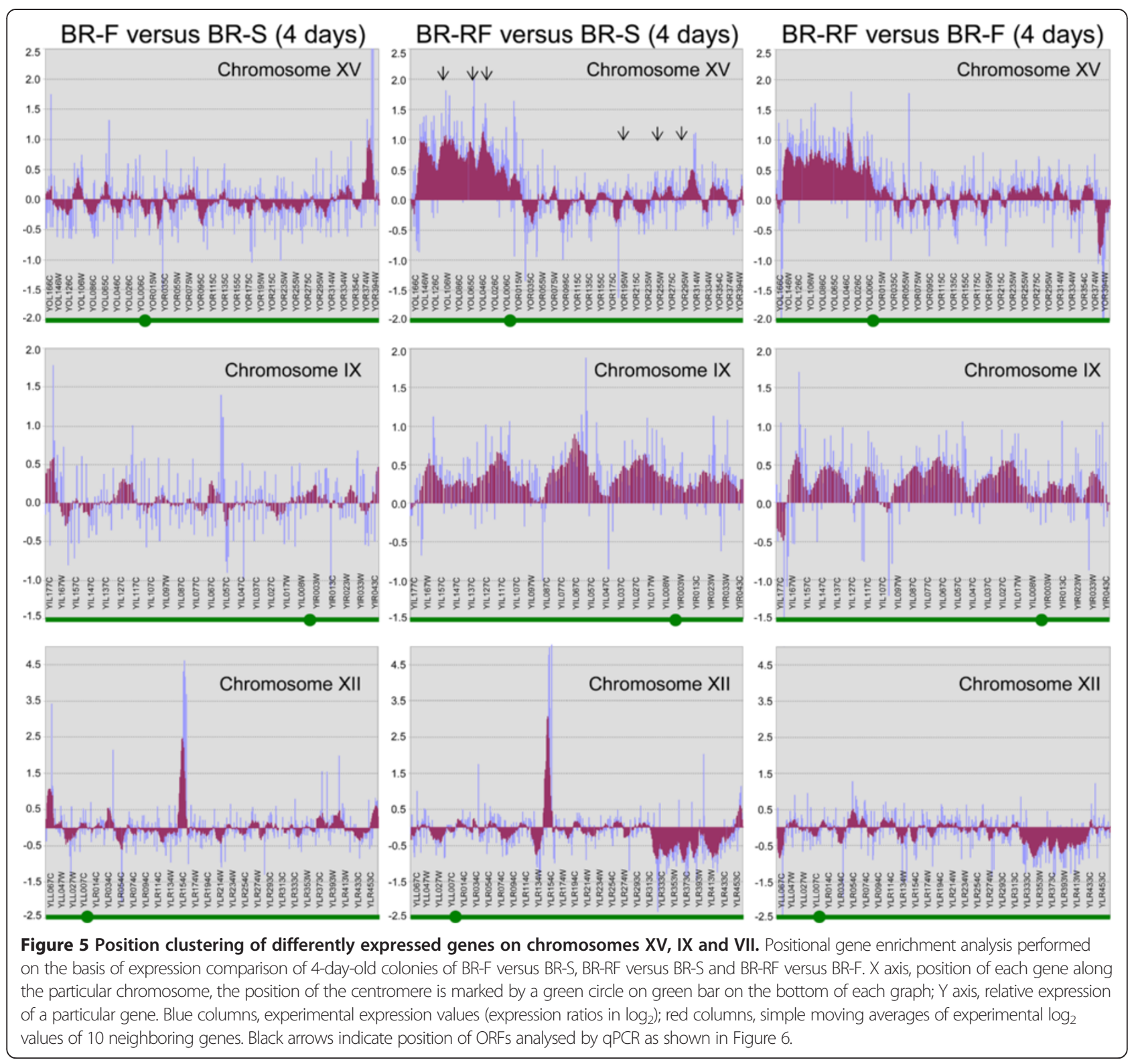

chromosome using real time qPCR. The results (Figure 6) showed significant differences between gene copy numbers in the left and right arms of chromosome XV in BR$\mathrm{RF}$ indicating partial genome duplications.

\section{BR-F colonies up-regulate expression of genes located in HAST domains, which affect BR-F stress resistance}

Analysis of the differently expressed genes revealed that some are localized near telomeres. It has been hypothesized that transitions between different phenotypes are controlled by transcriptional silencing via specific chromatin-remodeling enzymes $[18,19]$. Thus, we compared the genes that were expressed differently in the BR-F, BR-S and BR-RF colonies with the list of genes expressed differently in a mutant containing a deletion of SIR2 [20], the gene encoding histone deacetylase. Histone deacetylase Sir2p has been shown to affect transcription at specific chromosomal locations near telomeres [21]. This analysis revealed a correlation between the genes down-regulated in the sir $2 \Delta$ strain and the genes typically expressed in colonies with a biofilm phenotype (29\% of genes up-regulated in 4-day-old structured biofilm colonies). However, neither the structured colony morphology nor the domestication rate of the BR-F-sir2 strain (in which both SIR2 alleles were deleted) was changed when compared with the BR-F strain (data not shown). This result implies that the function of Sir2p is not important for the formation of structured colony morphology.

Next, we compared our set of genes with a database of genes specified to be under the control of another 


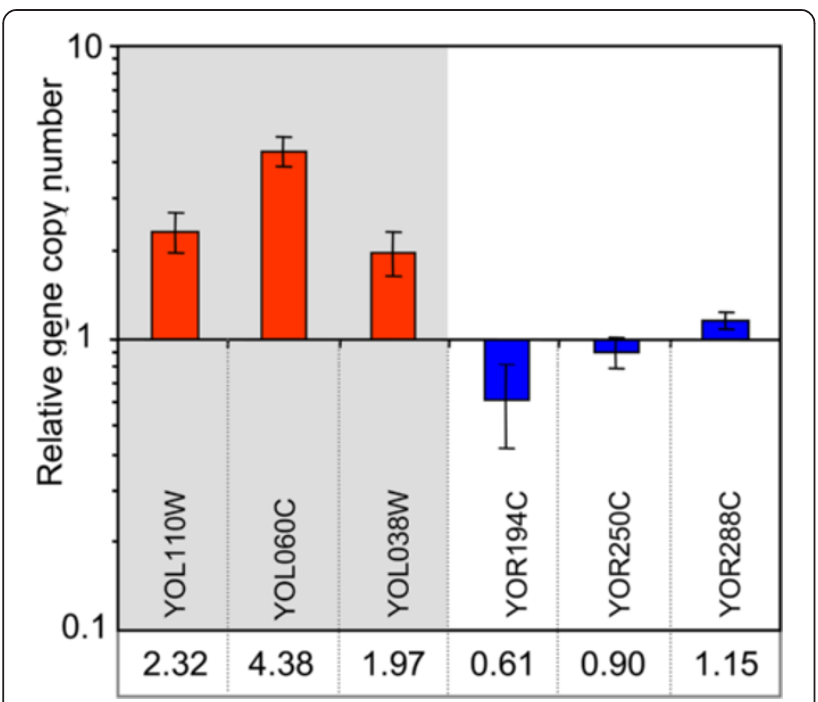

Figure 6 Relative copy number of genes located on the left and right arm of chromosome $\mathrm{XV}$ in BR-RF versus BR-S.

Comparison of relative copy number was performed by qPCR using chromosomal DNA isolated from BR-RF and BR-S strains. Positions of examined genes on chromosome XV are marked by black arrows at Figure 5. Red, genes located at the left arm of the chromosome XV the expression of which is upregulated in BR-RF when compared with BR-S (and BR-F); blue, genes located at the right arm of the chromosome $\mathrm{XV}$. Y axis, relative gene copy number (BR-RF versus BR-S); the exact values are stated below the ORFs. The mean of values from 3 independent experiments \pm SD are shown; data significance (relative copy number of each left-arm-gene compared to relative copy number of each right-armgene) was determined using the two-tailed $t$ test. All $\mathrm{P}$ values varied between $P<0.05$ and $P<0.005$.

deacetylase, Hda1p. Hdalp was shown to cause transcriptional repression in specifically localized subtelomeric chromosomal regions [22]. This analysis revealed a correlation between the genes localized to HAST domains, i.e., regions controlled by Hda1p histone deacetylase [22], and the genes up-regulated in BR-F colonies. In particular, $18 \%$ of the genes up-regulated in BR-F versus BR-S colonies, $19 \%$ of genes up-regulated in BR-F versus BR-RF colonies and $32 \%$ of genes up-regulated in BR-F versus both BR-RF and BR-S 4-day-old colonies were localized to these domains. In contrast, upregulation of HAST domain genes in BR-S and BR-RF colonies versus BR-F colonies was less than $6 \%$. Thus, the upregulation of these genes in BR-F colonies indicated decreased activity of Hda1p compared to BR-S and BR-RF colonies.

Genes in the HAST domains that were specifically upregulated in the BR-F strain (Figure 7A) included genes encoding various glucosidases (8 genes), proteins with mostly unknown function and predicted localization to the cell wall (11 genes) and various transporters (8 genes). These data indicated that the cells in the BR-F colonies could have specific cell wall and plasma membrane properties compared to the BR-S and BR-RF colonies; however, these properties seemed unrelated to the structured biofilm colony phenotype. To test this prediction, we prepared the strain BR-S-hda1, with both alleles of the HDA1 gene deleted, which should de-repress HAST domain genes. We then analyzed the morphology of colonies of this strain and the resistance to various stresses compared with the BR-F, BR-RF and BR-S strains (Figure 7B). The BR-S-hda1 strain formed smooth colonies similar in morphology but slightly larger than colonies of the BR-S strain of the same age (Figure 7B). Similarly to the BR-F strain, the BR-S-hdal strain was significantly more resistant to the chitin binding dye calcofluor white, and it grew better at a higher temperature $\left(37^{\circ} \mathrm{C}\right)$ than either the BR-S or the BR-RF strain. Thus, deletion of the HDA1 gene in the BR-S strain increased its calcofluor white and temperature resistance to the same level as the BR-F strain, but it did not change the smooth colony morphology.

\section{Discussion}

Wild S. cerevisiae strains are able to effectively domesticate when transferred to favorable laboratory conditions $[13,14]$. Here, we show that the BR-S strain can switch back to a wild-type-like phenotype and start to form structured biofilm colonies following long-term exposure to starvation and stress conditions. In contrast to the original BR-F strain, which forms structured colonies with a uniform morphology, our isolated feral BR-S subclones form colonies with different phenotypes. Thus, the increased phenotypic variability of the feral BR-S subclones seems to be induced by environmental stress and starvation. These data agree with previous findings that non-isogenic S. cerevisiae strains isolated from various habitats can form differently structured colonies [14], similarly to pathogenic fungi [5].

The first feral subclones of the BR-S strain appear after approximately 30 days of slow growth in static cultures with limited nutrients. Later, the proportion of subclones increases up to $26 \%$ of the viable cells in some of the parallel cultivations. At least between days 75 and 110, such an increase could be caused by an increased rate of phenotypic switching as well as by the preferential dying of smooth cells during the "loss of viability" phase of the population growth curve (Figure 1A). The number of feral cells starts to decrease from day 115 , i.e. 40 days later that in the case of domesticated cells. These findings suggest that feral subclones gain the ability to better survive starvation than domesticated cells. Higher concentrations of a better carbon source (e.g., fructose) block the emergence of subclones forming structured colonies, thus indicating the importance of nutrient restriction for the evolution of feral subclones. Similarly, various stress factors promote phenotypic switching of $C$. albicans, resulting in the production of cell variants that are more resistant to stresses [23]. Exposure of C. neoformans cells to various host defense mechanisms in vivo also leads to phenotypic modulation of an originally homogeneous population and 
A

\begin{tabular}{ll}
\hline & \multicolumn{1}{c}{ HAST domain genes induced in BR-F } \\
\hline Cell wall & YAR066W, PAU13, YAR062W, YHR213W, FIT2, FIT3, PAU1, \\
& PAU12, PAU24, YAR061W, PAU20 \\
\hline Metabolism & BIO5, JLP1, SOR1, BAT2, BDH2, BIO3, GDH3, ERR3, GDH1 \\
\hline Glucosidases & IMA1, YIL169C, YJL216C, FSP2, IMA2, IMA3, MAL32, MAL12 \\
\hline Transport & MPH3, YCT1, ZRT1, AQY1, FET4, MAL31, AQY2, ARN2 \\
\hline Unknown & YHR210C, YFL051C, YJL220W, REE1, COS5 \\
\hline
\end{tabular}

B

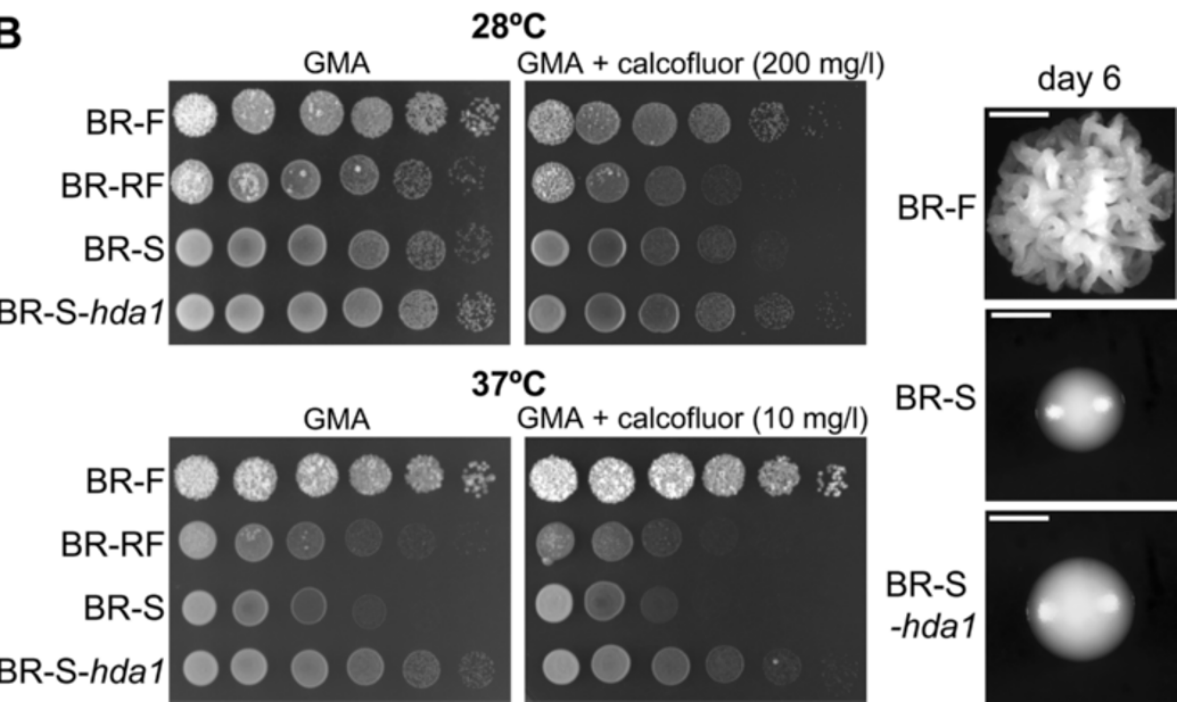

Figure 7 Derepression of HAST domain genes. A. Genes localized to HAST domains [22] up-regulated specifically in 4- and 7-day-old BR-F colonies compared to both BR-RF and BR-S colonies. Genes only expressed differently on the 4th day are in standard letters, genes expressed differently on both the 4th and 7th day are in bold and genes only expressed differently on the 7th day are italicized. B. Left, drop assays of cells from BR-F, BR-RF, BR-S and BR-S-hda1 colonies plated on GMA supplemented with calcofluor white and grown at $28^{\circ} \mathrm{C}$ and $37^{\circ} \mathrm{C}$ as indicated. Right, 6-day-old colonies of BR-F, BR-S and BR-S-hdal strains. Scale bar $=1 \mathrm{~mm}$.

to the subsequent prevalence of variants that are more resistant to the host immune response [6].

A BR-RF strain forms structured colonies with a morphology that is visually identical to that of the colonies formed by the original wild BR-F strain. The BR-RF strain, however, differs in several aspects from the BR-F strain. First, the BR-RF strain domesticates 4 times more effectively on fermentable media and 8 times more effectively on respiratory media than the BR-F strain. This finding suggests that the several months of starvation are sufficient to induce the formation of feral subclones but are not sufficient to make the feral subclones as stable as the original BR-F strain, which evolved over a much longer time in a natural setting. This finding also agrees with the results from some feral subclones that emerged during static cultivation (Figure 1B); these subclones form less structured colony phenotypes that are even more unstable and quickly revert back to the domesticated phenotype.
The data also demonstrate that the presence of a good fermentable carbon source such as glucose efficiently promotes the domestication of both strains (Figure 1C) and prevents the switch to a structured phenotype as indicated above.

Second, the colonies of the BR-RF strain differ from the colonies of both the BR-F and BR-S strains in certain physiological parameters, behaving as an "intermediate" between the BR-F and BR-S colonies (Figure 2). Similarly to the BR-S strain, the BR-RF strain also forms oval cells and is not able to form the elongated cells and pseudohyphae that are typical of the BR-F strain. This finding supports the idea that the particular cell morphology is a dispensable factor in the formation of biofilm colony architecture [14].

On the other hand, both the formation of the ECM and the production of Flo11p adhesin, the traits important for the formation of structured colony morphology [14], recover in BR-RF colonies. The length of the FLO11 transcript, however, differs from the original BR-F and the feral BR-RF 
strains. Recombination of the central repeat domain of the yeast adhesin genes is frequently observed [24], which often leads to the generation of a protein with different and/or enhanced adhesive function [25]. The change in the FLO11 gene of the BR-F strain most likely occurs during the domestication process; the FLO11 transcript, although present at very low levels in BR-S colonies, is the same size in both the BR-S and BR-RF strains. Thus, it seems that rather than actual gene size and potentially protein size, the Flo11p expression level is important in the context of structured colony formation. The altered FLO11 transcript length also indicates that DNA recombination may occur frequently during phenotypic transitions of the BR-F strain. This conclusion is further supported by the observed differences in the MW of the HMWGP protein component of the ECM (Figure 3), which could be caused by different posttranslational modifications or by changes in gene structure. In summary, these data show that the BR-RF strain, which was selected under the conditions of long-term nutrient deprivation and stress, develops some properties similar to the BR-F strain (e.g., the formation of structured biofilm colony morphology) but also maintains some properties of the BR-S strain (e.g., the formation of oval cells).

Genome-wide transcriptome analysis allows us to determine the typical gene expression profile for a structured colony phenotype compared with the smooth phenotype. Structured biofilm colonies (BR-F and BR-RF) both upregulate and down-regulate distinct genes involved in cell wall remodeling as well as genes involved in the delivery and modification of secreted and cell wall/membrane-attached proteins. This finding indicates that, in addition to Flo11p adhesin, the carbohydrate composition of the cell wall, the appearance of specific surface proteins and protein glycosylation may affect specific properties of the cells (such as the production of the ECM) and contribute to the formation of a biofilm colony. Ty transposon genes and several unknown genes that are expressed in biofilm colonies are located in subtelomeric regions. This suggests that transcription of genomic regions that are influenced by chromatin structure [26] differs in biofilm colonies compared to smooth colonies. In support, smooth colonies up-regulate the expression of a group of genes involved in histone modification and chromatin remodeling (Table 1).

There is further evidence of the importance of chromatin remodeling in the diversification of properties of phenotypic variants derived from the BR-F strain. BR-F colonies (but not BR-RF colonies) express genes located in HAST domains, i.e., regions in the genome whose expression is modulated by histone deacetylase Hda1p [22]. Deletion of the HDA1 gene (and thus de-repression of HAST domain genes) significantly increases the resistance of BR-S cells to both calcofluor white and high temperature, thereby reaching the level of resistance of the BR-F strain. Calcofluor white interferes with cell wall assembly [27], and strains with mutations that affect the cell wall composition are more sensitive to calcofluor white [28]. Thus, the resistance of the BR-F strain could be caused by expression of HAST domain genes encoding various cell wall and plasma membrane-related proteins. In support of persistent repression of HAST domain genes in BR-RF colonies, cells from BR-RF colonies behave similarly to BR-S cells. On the other hand, de-repression of HAST domain genes in BR-S-hdal colonies does not affect the smooth morphology of these colonies, indicating that HAST domain genes expressed in the BR-F strain are unrelated to the biofilm colony phenotype. However, other studies demonstrate the role of specific deacetylases, including Hda1p, in controlling the phenotypic transition of the "white-opaque" C. albicans colony [18,29]. Hence, epigenetic mechanisms mediated by chromatin remodeling enzymes have the capacity to regulate phenotypic heterogeneity.

In addition to the expression characteristics specific to structured biofilm colonies, gene expression specific to BR-RF colonies is related to three regions of the BR-RF genome. This finding indicates that some chromosome rearrangements occur during BR-RF strain formation; these could result in the duplication of certain parts of chromosomes or in chromosomal rearrangement(s) relocating the regions to more actively transcribed locations of the genome. Real time qPCR comparison of relative copy number of three genes located in the left arm of chromosome XV that upregulate expression in BR-RF (YOL110W, $Y O L O 60 C$ and $Y O L O 38 \mathrm{~W}$ ) with that of three genes located in the right arm of the same chromosome (YOR194C, YOR250C, YOR288C), indicates large duplications in the genome (Figure 6). This finding also agrees with previous observations that diverse conditions can evoke aneuploidy in yeast, which can directly impact gene expression, as detected at both the transcriptional and proteomic levels [30,31], and can also modulate the switch between different colony phenotypes [32]. However, the observed chromosome site-specific expression characteristics of the BR-RF strain are unrelated to the structured colony phenotype, as only a few biofilm colony-specific genes are localized to these chromosomal regions. DNA rearrangement events leading to karyotypic instability are also observed during phenotypic transitions of certain C. albicans [33] and C. neoformans strains [8]. These previously observed changes are not correlated with phenotypic variability and are irreversible. Thus, it seems that DNA rearrangements resulting in particular gene expression changes are not the cause of the BR-F/ BR-S/BR-RF phenotypic switch, which is in contrast to recent findings in other wild strains [32]. Instead, these rearrangements in the BR-RF strain could be a sideproduct of the increased rate of recombination events that occur during the phenotype transitions. 


\section{Conclusions}

We describe the phenotypic, genomic and gene expression differences among three $S$. cerevisiae strains (wild, domesticated and feral) that emerged by phenotypic switching under diverse environmental conditions. These strains form colonies with varying complexity and gain diverse features including altered resistance to stress. We show that the wide variability of natural S. cerevisiae strains can be further potentiated under stressful environmental conditions. We identify genes specifically expressed in the structured colony phenotype, such as genes that specifically affect the composition of cell surface structures; these genes provide clues as to the specific processes involved in the formation of structured colony architecture. We also document a role of Hdalp histone deacetylase in strain resistance to stress. In addition, our data indicate that genomic rearrangement(s) occur in the feral strain that are unrelated to the phenotypic switch. These changes contribute to expression characteristics of the feral strain that are distinct from both its ancestors, the wild and domesticated strains.

In summary, our findings show that extensive phenotypic modulation occurs in wild S. cerevisiae strains. Phenotypic switching can be controlled by various mechanisms and enables flexible adaptation of these strains to a particular environment in the wild. The comparison of the three originally isogenic strains BR-F, BR-S and BR-RF revealed many significant gene expression and phenotypic differences, but only a few of them seem to be related to the formation of structured biofilm colonies. In addition, the differences observed between BR-F and BR-RF showed that reverted structured colony morphology does not necessarily mean reversion of other strain properties. In other words, strains with different properties such as BR-F and BR-RF can form structured colonies. Thus, an important question remains as to whether there is a single dominant mechanism that forces yeast strains to form structured colonies independently of other properties or, more probably, a variety of mechanisms that support the formation of structured colony morphology.

\section{Methods}

\section{Strains and media}

All strains and their derivatives are listed in Additional file 2: Table S2. The wild S. cerevisiae strain BR-F, originally collected from the lake in south Slovakia [34] is from the collection of the Chemical Institute of the Academy of Science, Bratislava, Slovak Republic (collection number CCY 21-4-97). The BR-RF and BR-S strains are isogenic to the BR-F strain and arose from phenotypic switching. Colonies were grown on GMA ( $3 \%$ glycerol, $1 \%$ yeast extract, $2 \%$ agar) or YEGA ( $2 \%$ glucose, $1 \%$ yeast extract, $2 \%$ agar) media at $28^{\circ} \mathrm{C}$ unless otherwise indicated. For static cultivations, we used liquid minimal medium (MM) $(0.5 \%$
$\left(\mathrm{NH}_{4}\right)_{2} \mathrm{SO}_{4}, 0.1 \% \mathrm{KH}_{2} \mathrm{PO}_{4}, 0.05 \% \mathrm{MgSO}_{4}$, pH 5-6.5) supplemented with ethanol $(0.1 \%, 0.5 \%, 1 \%, 2 \%$ and $3 \% \mathrm{v} / \mathrm{v})$, fructose $(0.2 \%, 0.5 \%, 1 \%$ and $2 \%)$ or $\mathrm{NaNO}_{3}(0.01 \% \mathrm{w} / \mathrm{v})$. For selective plates, media were supplemented with $200 \mathrm{mg} / \mathrm{l} \mathrm{G} 418$ or $100 \mathrm{mg} / \mathrm{l}$ nourseothricin.

\section{Static cultivations, determination of CFU and percentage of cells that switched to form biofilm colonies}

The BR-S strain was inoculated into MM medium at a concentration of approximately $5 \times 10^{5}$ cells per $\mathrm{ml}$. The cell culture was split into $10 \mathrm{ml}$ portions in glass tubes (3 to 10 parallels for each particular concentration of the supplements) and statically cultivated at $28^{\circ} \mathrm{C}$. During long-term cultivation, the culture was mixed at particular timepoints. After appropriate dilution, $100 \mu \mathrm{l}$ aliquots were plated on GMA to determine the number of CFU and the proportion of cells forming structured biofilm colonies.

\section{Construction of the strains}

Flo11p-GFP strains containing the FLO11 gene fused with the GFP gene were constructed via a previously described procedure [17]. The BR-RF strain with an artificial promoter $\mathrm{P}_{\mathrm{GAL1} 1}$-GFP cassette integrated in the genome instead of the HIS3 gene was constructed as previously described [16]. Gene knock-outs were performed by transforming the cells with deletion cassettes generated by PCR using the primers and plasmids listed in Additional file 2: Table S3. Yeast cells were transformed according to a published protocol [35].

\section{Determination of colony biomass}

The biomass of colonies was estimated as their wet weight. To determine dry biomass, the wet biomass was dried in a Speed-Vac for at least $6 \mathrm{~h}$. The water content was calculated as the difference between the wet and dry biomasses. The data were presented as the average of three independent experiments \pm SD (standard deviation).

\section{Determination of switching frequency}

The occurrence of switching from the BR-F and BR-RF to the BR-S colony phenotype was determined by visually scoring the colonies of different ages growing either on GMA or on YEGA media. To calculate the switching frequencies, 100-200 BR-F and BR-RF cells were plated on GMA plates, and at least 5000 colonies were scored. The percentage of colonies of the total CFU with smooth morphology was determined.

\section{Fluorescence microscopy of cells and colony imaging}

Cells were examined under a Leica DMR microscope equipped with a $100 \times / 1.3$ oil objective and a GFP filter or Nomarski contrast and photographed with a ProgRes ${ }^{\circ}$ $\mathrm{MF}^{\mathrm{cool}} \mathrm{CCD}$ camera (Jenoptik, Germany). Colony images were captured in incident light. A ProgRes ${ }^{\circ}$ CT3 CMOS camera with a Navitar objective, Fiber-Lite PL-800 
illumination system and NIS Elements software (Laboratory Imaging) were used.

\section{Sensitivity of the strains to calcofluor white}

The strain sensitivity was tested by the drop assay. Four-day-old colonies were harvested to make a suspension containing $2 \times 10^{8}$ cells per ml. Next, $5 \mu \mathrm{l}$ drops of 10-fold serial dilutions were applied to GMA plates supplemented with $10 \mathrm{mg} / \mathrm{l}$ or $200 \mathrm{mg} / \mathrm{l}$ calcofluor white. Plates were scored after 3 days of incubation at $28^{\circ} \mathrm{C}$ or $37^{\circ} \mathrm{C}$.

\section{Northern blot analysis}

Total RNA from the cells of colonies grown on GMA plates was isolated by the hot phenol method as previously described [14]. For northern blots, $12 \mu \mathrm{g}$ of total RNA was separated on a $1.5 \%$ agarose gel, transferred to a positively charged nitrocellulose membrane (Hybond-XL, Amersham Bioscience) and exposed to a labeled probe. The radioactive signal was visualized on Fuji X-ray film. The DNA probe for the RDN18 gene was a complete ORF of the gene prepared by PCR reaction. For the FLO11 probe, a PCR fragment corresponding to the last $1382 \mathrm{bp}$ of the FLO11 gene was used. The $\left[\alpha-{ }^{32} \mathrm{P}\right] \mathrm{dCTP}$-labeled probes were obtained by random priming using the DecaPrime II Kit (Ambion).

\section{Microarray analysis}

The mRNA was isolated from total RNA using a Micro-Fast track 2.0 Kit (Invitrogen). Reverse transcription was performed from $2-4 \mu \mathrm{g}$ of mRNA as previously described [36]. Labeled cDNA was applied to Yeast 6.4 K Array (Y6.4 K) double spotted ORF slides (University Health network, Toronto, Canada) following the manufacturer's instructions and incubated overnight at $37^{\circ} \mathrm{C}$. The arrays were washed according to the manufacturer's protocol and scanned using an Axon fluorescent scanner and the GenePix software. Three double-genome microarrays (biological replicates) were used. Spots were detected using the TIGR Spotfinder (TM4.org) software and normalized in TIGR MIDAS (TM4.org) using the LOWESS method. Differentially expressed genes were selected using a combined fold-change and ANOVA analysis using $\mathrm{MeV}$ software (TM4.org). Genes exhibiting an at least 1.5-fold change $\left(\log _{2}>0.585\right)$ in their average expression and simultaneously a p-value $<0.05$ were considered to be differentially expressed.

\section{Extracellular material extraction, SDS-PAGE and detection of protein glycosylation}

Extracellular material was extracted as previously described [14]. After SDS-PAGE separation, extracellular proteins were stained with silver [37] or transferred to a PVDF membrane. Glycoproteins were visualized by sequential incubation in concanavalin $\mathrm{A}$, horseradish peroxidase and chloronaphthol $\mathrm{H}_{2} \mathrm{O}_{2}$ solution [38].

\section{Two-photon excitation confocal microscopy (2P-CM)}

Vertical transverse cross-sections of colonies were prepared and their side-views obtained by $2 \mathrm{P}-\mathrm{CM}$ as described previously [39]. The cross-sections were stained with Concanavalin A conjugated with Alexa Fluor 488 (ConA-AF; $30 \mu \mathrm{g} / \mathrm{ml}$ ). Alternatively, GFP fluorescence was monitored. Images were acquired with a Leica TCS SP2 AOBS MP confocal laser scanning microscope fitted with a mode-locked Ti: Sapphire Chameleon Ultra laser (Coherent Inc., Santa Clara, CA, USA) for twophoton excitation as previously described [16].

Real time quantitative PCR (qPCR) analysis of genomic DNA Three target genes were selected from those in the left arm of chromosome XV with apparently upregulated expression in strain BR-RF compared with BR-S and three reference genes were selected from those in the right arm of chromosome XV with no significant difference in expression (Figure 5). Primers (Additional file 2: Table S4) were designed using the GenScript real time qPCR primer design tool (https://www.genscript.com/ssl-bin/app/primer). Stipulated parameters included an amplicon length of 90-110 bp and melting temperature of $60-65^{\circ} \mathrm{C}$. Primers were selected with a GC content of 40-60\%, a length of 19-21 bp and minimal self-complementarity when analyzed using OligoCalc (http://www.basic.northwestern.edu/biotools/oligocalc.html [40]). DNA extraction was carried out according to the method of [41]. Real time qPCR was carried out on the light cycler 480 II (Roche, Basel) using FAST START Sybr Green (Roche, Basel), forward and reverse primers (final concentration $500 \mathrm{nM}$ ) and genomic DNA (20 ng per $20 \mu \mathrm{l}$ reaction) from strain BR-RF or strain BR-S (or water in negative controls). An initial melting/activation step at $95^{\circ} \mathrm{C}$ for 5 min was followed by 45 cycles of melting, annealing and amplification $\left(95^{\circ} \mathrm{C}\right.$ for $30 \mathrm{~s}, 56^{\circ} \mathrm{C}$ for $30 \mathrm{~s}$ and $72^{\circ} \mathrm{C}$ for $30 \mathrm{~s}$ ) with a fluorescence measurement $(465-510 \mathrm{~nm})$ at the end of each amplification step. Raw data were analyzed using the comparative delta CT method [42]. The relative gene copy number is $2^{\Delta \mathrm{CT}}$, where $\Delta \mathrm{CT}=\left(\mathrm{CT}_{\mathrm{BR}-\mathrm{S}}-\mathrm{CT}_{\mathrm{BR}-\mathrm{RF}}\right)$.

\section{In silico analysis of gene sets obtained by microarray comparison}

Genes were classified into functional categories using the particular gene description in the Saccharomyces genome database available at http://www.yeastgenome.org/. Enrichment of the gene sets at particular chromosomal regions was determined by Positional Gene Enrichment analysis using the online tool available at http://homes. esat.kuleuven.be/ bioiuser/pge [43]. 


\section{Availability of supporting data}

The data sets supporting the results of this article are available in the NCBI GEO repository (accession number GSE40625, http://www.ncbi.nlm.nih.gov/geo/query/ acc.cgi?acc=gse40625).

\section{Additional files}

Additional file 1: Table S1. List of genes differentially expressed comparing transcriptomes of cells from 4- and 7-day-old BR-F, BR-RF and BR-S colonies. Differentially expressed genes were selected on the basis of combined criteria of fold-change (0.585 on $\log 2$ scale) and p-value $(<0.05)$. Gene sets obtained from comparison of each phenotype couple (BR-F $\times$ BR-S, BR-F $\times$ BR-RF and BR-S $\times$ BR-RF) for both 4- and 7-day-old colonies are on a separate $x \mathrm{Is}$ list.

Additional file 2: Table S2. List of strains used in this study. Table S3. List of primers and plasmids used in the strain construction. Table S4. List of primers used in $\mathrm{GPCR}$

\section{Competing interests}

The authors declare that they have no competing interests.

\section{Authors' contributions}

$Z P, L V$, VS and DW conceived and designed the study. VS, MB, DW, ZP and LV performed the experiments. VS, ZP, LV, DW and MB analyzed the data. $Z P, L V, V S$ and DW wrote the paper. All authors read and approved the final manuscript.

\section{Acknowledgments}

This study was supported by the Grant Agency of the Czech Republic 13-08605S, the Ministry of Education MSM0021620858, Charles University in Prague (UNCE 204013), RVO 61388971 and European Social Fund and the state budget of the Czech Republic (CZ.1.07/2.3.00/30.0061). This publication is also supported by the project "BIOCEV - Biotechnology and Biomedicine Centre of the Academy of Sciences and Charles University" (CZ.1.05/1.1.00/ 02.0109), from the European Regional Development Fund. We thank A. Pokorná for her excellent technical assistance.

\section{Author details}

${ }^{1}$ Department of Genetics and Microbiology, Faculty of Science, Charles University in Prague, Viničná 5, 12844 Prague 2, Czech Republic. ${ }^{2}$ Institute of Microbiology of the ASCR, v.v.i., Vídeňská 1083, 14220 Prague 4, Czech Republic. ${ }^{3}$ Current Address: The Novo Nordisk Foundation Center for Biosustainability, Technical University of Denmark, Kogle Alle 6, 2970 Hørsholm, Denmark.

Received: 1 August 2013 Accepted: 7 February 2014 Published: 17 February 2014

\section{References}

1. Palková Z: Multicellular microorganisms: laboratory versus nature. EMBO Rep 2004, 5(5):470-476.

2. van der Woude MW: Re-examining the role and random nature of phase variation. FEMS Microbiol Lett 2006, 254(2):190-197.

3. Soll DR: High-frequency switching in Candida albicans. Clin Microbiol Rev 1992, 5(2):183-203

4. Soll DR: Candida commensalism and virulence: the evolution of phenotypic plasticity. Acta Trop 2002, 81(2):101-110.

5. Jain N, Hasan F, Fries BC: Phenotypic switching in fungi. Curr Fungal Infect Rep 2008, 2(3):180-188.

6. Fries BC, Taborda CP, Serfass E, Casadevall A: Phenotypic switching of Cryptococcus neoformans occurs in vivo and influences the outcome of infection. J Clin Invest 2001, 108(11):1639-1648.

7. Kvaal C, Lachke SA, Srikantha T, Daniels K, McCoy J, Soll DR: Misexpression of the opaque-phase-specific gene PEP1 (SAP1) in the white phase of Candida albicans confers increased virulence in a mouse model of cutaneous infection. Infect Immun 1999, 67(12):6652-6662.
8. Goldman DL, Fries BC, Franzot SP, Montella L, Casadevall A: Phenotypic switching in the human pathogenic fungus Cryptococcus neoformans is associated with changes in virulence and pulmonary inflammatory response in rodents. Proc Natl Acad Sci USA 1998, 95(25):14967-14972.

9. Slutsky B, Staebell M, Anderson J, Risen L, Pfaller M, Soll DR: "White-opaque transition": a second high-frequency switching system in Candida albicans. J Bacteriol 1987, 169(1):189-197.

10. Ramirez-Zavala B, Reuss O, Park YN, Ohlsen K, Morschhauser J: Environmental induction of white-opaque switching in Candida albicans. PLoS Pathog 2008, 4(6):e1000089.

11. Granek JA, Magwene PM: Environmental and genetic determinants of colony morphology in yeast. PLoS Genet 2010, 6(1):e1000823.

12. Granek JA, Murray D, Kayrkci O, Magwene PM: The genetic architecture of biofilm formation in a clinical isolate of Saccharomyces cerevisiae. Genetics 2013, 193(2):587-600.

13. Kuthan M, Devaux F, Janderová B, Slaninová I, Jacq C, Palková Z: Domestication of wild Saccharomyces cerevisiae is accompanied by changes in gene expression and colony morphology. Mol Microbiol 2003, 47(3):745-754

14. Štovíček V, Váchová L, Kuthan M, Palková Z: General factors important for the formation of structured biofilm-like yeast colonies. Fungal Genet Biol 2010, 47(12):1012-1022.

15. Voordeckers K, De Maeyer D, van der Zande E, Vinces MD, Meert W, Cloots L, Ryan O, Marchal K, Verstrepen KJ: Identification of a complex genetic network underlying Saccharomyces cerevisiae colony morphology. Mol Microbiol 2012, 86(1):225-239.

16. Váchová $L$, Štovíček V, Hlaváček $\mathrm{O}$, Chernyavskiy $\mathrm{O}$, Štěpánek L, Kubínová L, Palková Z: Flo11p, drug efflux pumps, and the extracellular matrix cooperate to form biofilm yeast colonies. J Cell Biol 2011, 194(5):679-687.

17. Vopálenská I, Štovíček V, Janderová B, Váchová L, Palková Z: Role of distinct dimorphic transitions in territory colonizing and formation of yeast colony architecture. Environ Microbiol 2010, 12(1):264-277.

18. Srikantha T, Tsai L, Daniels K, Klar AJ, Soll DR: The histone deacetylase genes HDA1 and RPD3 play distinct roles in regulation of high-frequency phenotypic switching in Candida albicans. J Bacterio/ 2001, 183(15):4614-4625.

19. Perez-Martin J, Uria JA, Johnson AD: Phenotypic switching in Candida albicans is controlled by a SIR2 gene. EMBO J 1999, 18(9):2580-2592.

20. Bedalov A, Gatbonton T, Irvine WP, Gottschling DE, Simon JA: Identification of a small molecule inhibitor of Sir2p. Proc Natl Acad Sci USA 2001 98(26):15113-15118.

21. Aparicio OM, Billington $B \mathrm{~L}$, Gottschling DE: Modifiers of position effect are shared between telomeric and silent mating-type loci in S. cerevisiae. Cell 1991, 66(6):1279-1287.

22. Robyr D, Suka Y, Xenarios I, Kurdistani SK, Wang A, Suka N, Grunstein M: Microarray deacetylation maps determine genome-wide functions for yeast histone deacetylases. Cell 2002, 109(4):437-446.

23. Alby K, Bennett RJ: Stress-induced phenotypic switching in Candida albicans. Mol Biol Cell 2009, 20(14):3178-3191.

24. Verstrepen KJ, Reynolds TB, Fink GR: Origins of variation in the fungal cell surface. Nat Rev Microbiol 2004, 2(7):533-540.

25. Fidalgo M, Barrales RR, Jimenez J: Coding repeat instability in the FLO11 gene of Saccharomyces yeasts. Yeast 2008, 25(12):879-889.

26. Rinckel LA, Garfinkel DJ: Influences of histone stoichiometry on the target site preference of retrotransposons Ty1 and Ty2 in Saccharomyces cerevisiae. Genetics 1996, 142(3):761-776.

27. Roncero C, Duran A: Effect of Calcofluor white and Congo red on fungal cell wall morphogenesis: in vivo activation of chitin polymerization. J Bacteriol 1985, 163(3):1180-1185.

28. Ram AF, Wolters A, Ten Hoopen R, Klis FM: A new approach for isolating cell wall mutants in Saccharomyces cerevisiae by screening for hypersensitivity to calcofluor white. Yeast 1994, 10(8):1019-1030.

29. Klar AJ, Srikantha T, Soll DR: A histone deacetylation inhibitor and mutant promote colony-type switching of the human pathogen Candida albicans. Genetics 2001, 158(2):919-924.

30. Pavelka N, Rancati G, Zhu J, Bradford WD, Saraf A, Florens L, Sanderson BW, Hattem GL, Li R: Aneuploidy confers quantitative proteome changes and phenotypic variation in budding yeast. Nature 2010, 468(7321):321-325.

31. Pfau SJ, Amon A: Chromosomal instability and aneuploidy in cancer: from yeast to man. EMBO Rep 2012, 13(6):515-527.

32. Tan Z, Hays M, Cromie GA, Jeffery EW, Scott AC, Ahyong V, Sirr A, Skupin A Dudley AM: Aneuploidy underlies a multicellular phenotypic switch. Proc Natl Acad Sci USA 2013, 110(30):12367-12372 
33. Slutsky B, Buffo J, Soll DR: High-frequency switching of colony morphology in Candida albicans. Science 1985, 230(4726):666-669.

34. Slavikova E, Vadkertiova R: Yeasts and yeast-like organisms isolated from fish-pond waters. Acta Microbiol Pol 1995, 44(2):181-189.

35. Gietz RD, Woods RA: Transformation of yeast by lithium acetate/singlestranded carrier DNA/polyethylene glycol method. Methods Enzymol 2002, 350:87-96.

36. Cap M, Stepanek L, Harant K, Vachova L, Palkova Z: Cell differentiation within a yeast colony: metabolic and regulatory parallels with a tumoraffected organism. Mol Cell 2012, 46(4):436-448.

37. Rabilloud T, Vuillard L, Gilly C, Lawrence JJ: Silver-staining of proteins in polyacrylamide gels: a general overview. Cell Mol Biol (Noisy-le-grand) 1994, 40(1):57-75.

38. Hawkes R: Identification of concanavalin a-binding proteins after sodium dodecyl sulfate-gel electrophoresis and protein blotting. Anal Biochem 1982, 123(1):143-146.

39. Váchová L, Chernyavskiy O, Strachotová D, Bianchini P, Burdíková Z, Ferč́ková I, Kubínová L, Palková Z: Architecture of developing multicellular yeast colony: spatio-temporal expression of Ato $1 p$ ammonium exporter. Environ Microbiol 2009, 11:1866-1877.

40. Kibbe WA: OligoCalc: an online oligonucleotide properties calculator. Nucleic Acids Res 2007, 35(Web Server issue):W43-W46.

41. Harju S, Fedosyuk H, Peterson KR: Rapid isolation of yeast genomic DNA: Bust n' Grab. BMC Biotechnol 2004, 4:8.

42. Pfaffl MW: A new mathematical model for relative quantification in real-time RT-PCR. Nucleic Acids Res 2001, 29(9):e45.

43. De Preter K, Barriot R, Speleman F, Vandesompele J, Moreau Y: Positional gene enrichment analysis of gene sets for high-resolution identification of overrepresented chromosomal regions. Nucleic Acids Res 2008, 36(7): 433 .

doi:10.1186/1471-2164-15-136

Cite this article as: Štoviček et al:: Global changes in gene expression associated with phenotypic switching of wild yeast. BMC Genomics 2014 15:136.

\section{Submit your next manuscript to BioMed Central and take full advantage of:}

- Convenient online submission

- Thorough peer review

- No space constraints or color figure charges

- Immediate publication on acceptance

- Inclusion in PubMed, CAS, Scopus and Google Scholar

- Research which is freely available for redistribution 